\title{
Pregnant Revisions Information Center for Maternal and Child Welfare in the Baghdad City about Benefit of Colostrum toward the New Born Baby
}

\author{
Dr. Abdul Mahdi A. Hassan*
}

\begin{abstract}
Background and aim: The first food for the baby after birth is colostrums. Therefore, the study aims to lays the importance of research in the identification information on the pregnant mother to the importance of colostrum, which is the first vaccine for her baby, which shields them from more than 28 diseases.

Materials and method: purposive sample study included 150 pregnant mothers who visiting the center of maternity and child care in the Sheikh Omar and care center in Al- Elwya Teaching Hospital, and Baghdad Teaching Hospital where the sample collected way Randomly and interview style dish and apply the Questionnaire form designed for this purpose based on scientific sources and previous studies for the period from $8 / 11 / 2011$ to $15 / 1 / 2012$. The validity through a panel review of experts. Data were analyzed using frequency distribution and percentage.

Results : the results show that $96 \%$ of respondents are housewives, while the proportion of female employees make up only $4 \%$.Accounted pregnant women at the first time revisions ratio of $24 \%$ of respondents while the percentage delivered women, the $76 \%$. As for the place of birth for the delivered women only figure was $38 \%$ for the birth of the house as well as the same percentage for the birth of the hospital.

Conclusion: The study that breastfeeding is the best source of nutrition for a healthy term infant. Human milk is human specific and contains nutrients that are essential for the proper growth and development of the newborn. For more, breast milk is beneficial to both infant and mother.
\end{abstract}

Key word: Pregnant women, benefit of colostrum, colostrum, New Born baby.

\section{INTRODUCTION}

Breastfeeding is the optimal source of nutrition. The Human Milk is specie specific and it provides all the essential nutrients necessary for the growth and development of the newborn infant (The Ministry of Public Health, 2009). The AAP, AAFP and WHO recommend exclusive breastfeeding for the first six months of life and continuous breastfeeding for at least 12 months of life(Midto, 2009). The Target of USDHHS "Healthy People 2010" initiative is to achieve breastfeeding at birth of $75 \%, 50 \%$ at 6 month and $25 \%$ at 12 months of life (WHO, 2010). In 2008 data published by the CDC shows that $77 \%$ of mothers in the US initiate breastfeeding at birth. Only about $30 \%$ of women continue with breastfeeding of the infant to six months of age (UNICEF, 2008). Home health is the most precious gift one can Submitted to the baby as it requires the baby to love and compassion and warmth that gives him his chest pain as far as what needs to nutritious food, and today, few people who deny the importance of breastfeeding and the fulfillment of needs emotional and physical for infants and in any case it is not always easy to shift from the theoretical to the application, particularly with regard to practices of artificial feeding (UNICEF, 2006). The health workers, doctors, midwives and nurses who have by virtue of their relations daily mothers, have a significant effect on the views of mothers and their behavior and decisions about infant feeding in the days critical first life of a newborn baby (WHO, 2010).

The first food for the baby after birth is colostrum, which is a resin yellow appearance may vary from or to another is the most suitable food for the baby during this period because it contains a high proportion of nutrients that he needs (The Ministry of Public Health, 2009).

The amount of colostrum a few, but enough to feed a baby, facilitate the process absorption and the bowel movement does not need the baby to any food or drink with him (UNICEF, 2008). The colostrum addition to being rich in many nutrients as well as factors anti-inflammatory that protects the child and the evils of infections during the first few days (Armstrong, 2005). So should workers in the field of health services that discourage people in some cultures and prevent him inhiption from resorting to some of the practices which excludes colostrum and the child is given water and sugar or honey water or other preparations (UNESCO, 2007; The Ministry of Public Health, 2009; Midto, 2009).

* Lecturer / Pediatric and Mental Health Nursing / College of Nursing / University of Babylon / abd_mahdi2003@yahoo.com 


\section{METHODOLOGY}

purposive sample study included 150 pregnant mothers who visiting the center of maternity and child care in the Sheikh Omar and care center in Al- Elwya Teaching Hospital, and Baghdad Teaching Hospital where the sample collected way Randomly and interview style dish and apply the Questionnaire form designed for this purpose based on scientific sources and previous studies for the period from $8 / 11 / 2011$ to $15 / 1 / 2012$. The validity through a panel review of experts. Data were analyzed using frequency distribution and percentage.

\section{RESULTS}

Table (1) age pregnant women visit the Centers for maternity and child care

\begin{tabular}{|c|c|c|}
\hline Age repetition pregnant & F & \% \\
\hline $18-22$ & 33 & $22 \%$ \\
\hline $23-27$ & 48 & $32 \%$ \\
\hline $28-32$ & 36 & $24 \%$ \\
\hline $33-37$ & 6 & $4 \%$ \\
\hline
\end{tabular}

Table (2) The participant educational level

\begin{tabular}{|l|c|c|}
\hline Achievement & F & \% \\
\hline Illiterate & 18 & $12 \%$ \\
\hline Primary & 75 & $50 \%$ \\
\hline Medium & 36 & $24 \%$ \\
\hline Secondary & 6 & $4 \%$ \\
\hline University & 15 & $10 \%$ \\
\hline Total & 150 & $100 \%$ \\
\hline
\end{tabular}

Table (3) The time to start breast-feeding after birth

\begin{tabular}{|l|l|l|}
\hline Time start lactation & F & $\mathbf{\%}$ \\
\hline Pregnant at the first time & 36 & $24 \%$ \\
\hline Breastfeed in less than 2 hours & 18 & $12 \%$ \\
\hline Breastfeed in the first day & 30 & $22 \%$ \\
\hline Suckling on the second day & 21 & $14 \%$ \\
\hline Suckling on the third day & 45 & $30 \%$ \\
\hline Total & 150 & $100 \%$ \\
\hline
\end{tabular}

Table (4) the nature of colostrum by male carries her.

\begin{tabular}{|l|c|c|}
\hline Article useful & $\mathbf{7 2}$ & $\mathbf{4 8 \%}$ \\
\hline A harmful substance & 42 & $28 \%$ \\
\hline don't know & 36 & $24 \%$ \\
\hline Total & 150 & $100 \%$ \\
\hline
\end{tabular}

Table (5) set ratchet addressed to pregnant revisions of care centers

\begin{tabular}{|l|l|l|l|l|l|l|}
\hline Questions & \multicolumn{2}{|c|}{ Yes } & \multicolumn{3}{|c|}{ No } & \multicolumn{2}{|c|}{ Total } \\
\cline { 2 - 7 } $\begin{array}{l}\text { addressed to the } \\
\text { pregnant women }\end{array}$ & F & \% & F & \% & F & $\%$ \\
\hline $\begin{array}{l}\text { Did the care center } \\
\text { to give advice }\end{array}$ & 150 & 100 & 144 & 96 & 6 & 4 \\
\hline
\end{tabular}

\begin{tabular}{|l|l|l|l|l|l|l|}
\hline $\begin{array}{l}\text { about the } \\
\text { usefulness of } \\
\text { colostrums }\end{array}$ & & & & & & \\
\hline $\begin{array}{l}\text { Did the midwife } \\
\text { center to give } \\
\text { advice about the } \\
\text { usefulness of } \\
\text { colostrums }\end{array}$ & 57 & 38 & 54 & 36 & 3 & 2 \\
\hline $\begin{array}{l}\text { Did the hospital to } \\
\text { give advice about } \\
\text { the usefulness of } \\
\text { colostrums }\end{array}$ & 57 & 38 & 54 & 36 & 3 & 2 \\
\hline $\begin{array}{l}\text { Expose to the } \\
\text { Health problems in } \\
\text { previous deliveries }\end{array}$ & 114 & 76 & 90 & 60 & 24 & 16 \\
\hline $\begin{array}{l}\text { Have you } \\
\text { encountered } \\
\text { trouble in the nurse } \\
\text { your baby }\end{array}$ & 114 & 76 & 105 & 70 & 9 & 6 \\
\hline $\begin{array}{l}\text { Does your child } \\
\text { maceration } \\
\text { feedings before } \\
\text { starting of breast } \\
\text { feeding }\end{array}$ & 114 & 76 & 12 & 8 & 102 & 68 \\
\hline
\end{tabular}

Table (6) colostrums interest by his mother said.

\begin{tabular}{|l|c|c|}
\hline Benefit of colostrums & F & $\%$ \\
\hline $\begin{array}{l}\text { Gives the baby's immunity against } \\
\text { diseases }\end{array}$ & 30 & 20 \\
\hline Laxative and cleans the intestines & 12 & 8 \\
\hline Easy digest & 3 & 2 \\
\hline Useful material for children & 6 & 4 \\
\hline Phytonutrient & 6 & 4 \\
\hline Strengthens the child's & 6 & 4 \\
\hline I don't know & 105 & 70 \\
\hline Total & 168 & $100 \%$ \\
\hline
\end{tabular}

\section{DISCUSSION}

The results show that $96 \%$ of respondents are housewives, while the proportions of female employees make up only 4\%. Accounted pregnant women for the first time. The revisions ratio of $24 \%$ of respondents while the percentage delivery the $76 \%$. As for the place of birth for the delivery only figure was $38 \%$ for the birth of the house as well as the same percentage for the birth of the hospital.

Perhaps the birth at the hospital safer in many ways for both mother and child, but they increase the probability of failure of lactation, reasons. Followed in a number of hospitals increase the likelihood of use of the mother complementary foods or stopped full breastfeeding as soon as she returned to the house (Midto, 2009).

As for the type of birth for delivered women was $60 \%$ natural birth, and $16 \%$ caesarean (causes birth dangerous) after the birth of ten and long may be the mother tired so can not breast-feeding directly, but he should remember that whenever 
some of the drugs given mother to breastfeed her baby The earlier the flow of milk. Often some of the drugs given during childbirth, especially in the caesarean section and the resulting delay in lactation unless accessible to mother special care in these cases (Midto, 2009).

Studies show through Table (1) that there are countries get where half of pregnancy among adolescents who are getting smaller as young as 18 years before they reach adulthood physical, mental and social, with results harmful, which is reflected on the mother and her newborn (UNESCO, 2007). The studies confirm through the Table (2) that women who receive a basic education, even if when a minimum different a generally more illiterate women that they feel the need to use available materials to improve their health and missed their families (UNESCO, 2007). Studies show through Table (3) that he should breast-feed the baby within an hour after birth if possible, because it is the first food for the baby after birth is colostrum which is the most suitable food for the baby during this period. It contains materials to help, and this is important for prevention such as that the importance baby food. This is for which child should suckle from his mother's breast immediately after birth or on at least during the first half hour of his life. The research also showed that mothers who produce in lactation pregnant at first time in breast-feeding a longer time than those who begin that process continuous after 12 hours or more (UNESCO, 2007; Midto, 2009; WHO, 2010). Through Table (4) shows that there must be health workers familiar with the beliefs of the communities in which they deal with their common practices and fight any of the myths that oppose breast feeding practices. That is where some civilizations are considered material colostrum and dirty teeth should be put. Some mothers escape from the first drops of colostrum, it only while put other women all colostrum produced during the first three days, and fed newborn with water and sugar or powdered milk which leads to depriving newborn vehicles cellular anti-infective, as well as to fit on proteins $65 \%$ of which are lethal to bacteria (Armstrong , 2005; WHO, 2009). Table (5) the results of the questions addressed to pregnant revisions of the Centre for Maternal and Child Welfare whether the center is to give advice to pregnant women about the benefit of colostrum, and the need to breast-feed newborn immediately after birth was the answer to that he lost $4 \%$ received advice from one of the doctors. As for midwives, only $2 \%$ were given advice by the midwife about the need to breast-feed newborn immediately after birth, as well as for those born in the hospital. Health workers to talk with the women attending the centers, whether in the outpatient clinic or health units, or by groupings within the health centers. As well as for midwives they are more and more people the ability to help the mother and her education must put their babies on the breast immediately after birth (Midto, 2009).

As for the breast and breast-feeding problems, the rate was $6 \%$ of those who faced troubles in breast-feed their babies as a result of problems in the nipple and breast suffocation. Studies show that most babies can breastfeed directly and easily, but few may have initially some difficulties in the process of sucking is that these problems go away in a few days (WHO, 2010). As for giving the newborn was feedings be glucose or water and sugar or powdered milk before giving him the breast was the proportion of yes constitute $68 \%$ of the mothers those the previous reproduction (UNICEF, 2003).

All studies show that the child in the first few days does not require water or powdered milk as many believe. Colostrum exists in the breast from the first moment which is all he needs (The Ministry of Public Health, 2009; WHO, 2010). Studies confirm and literature that colostrum contains a larger proportion of the antibodies and white blood cells is precisely what needs newborn because it gives him good protection against bacteria and viruses, which is rich in factors conducive to career growth of the gut has an impact Vairose helps to get rid of (meconium) meconium. It also contains concentrated amounts of some nutrients, especially protein, vitamin A, zinc and sodium (UNESCO, 2007; Midto, 2009).

\section{CONCLUSIONS}

The study concludes that health workers in all health institutions should be give advice and encourage mothers breast-feeding immediately after birth. In addition, breastfeeding is the best source of nutrition for a healthy term infant. Human milk is human specific and contains nutrients that are essential for the proper growth and development of the newborn. For more, breast milk is beneficial to both infant and mother. It also concludes Proper positioning on the breast helps ensure adequate latching on and subsequently adequate breastfeeding. Breast milk can be stored away, and utilized later when needed. Finally, there are absolute contraindications to breastfeeding, these include HIV, 1 and 11 , HTLV 1 and 11, active TB and active herpes simplex lesions on the breast.

\section{RECOMMENDATIONS}

The researcher recommended the preparation and implementation of an education program for pregnant mothers and medical and nursing owners for the purpose of providing them with the necessary 
information about the usefulness of colostrum for baby.

\section{REFERENCES}

Armstrong, H. (2005). A training manual in the management of breast milk. Beirut, Lebanon. Pp. 24.

Midto. (2009). Encourage moms to breastfeed. Beirut, Lebanon. Pp. 22-54.

The Ministry of Public Health. (2009). Breastfeeding happiness to you and to protect your child 2009 pp. 12-32.

UNESCO. (2007) .Feed the mother and the little boy. Paris. Pp. 32.
UNICEF. (2003). Dealing with and encourage breastfeeding. Baby-friendly hospit. Pp. 3036.

UNICEF. (2006). To protect the health of the baby. Amman, Jordan. Pp. 12-26.

UNICEF. (2008). Manual breastfeeding mothers in the successful. pp. 16 and 43-65.

World Health Organization (WHO). (2009). Breastfeeding and pregnancy spacin. Egypt, Alexandria. Pp. 35-44.

World Health Organization (WHO). (2010). Breastfeeding, Alexandria, Egypt, 2010. Pp. 33- 41. 